\title{
Strengthening Statistics Graduate Programs with Statistical Collaboration - The Case of Hawassa University, Ethiopia
}

\author{
Ayele Taye Goshu ${ }^{1}$, Ph.D. \\ ${ }^{1}$ Department of Statistics, School of Mathematical and Statistical Sciences, Hawassa University, Ethiopia \\ Correspondence: Ayele Taye Goshu, Ph.D., Department of Statistics, School of Mathematical and Statistical \\ Sciences, Hawassa University, Ethiopia. E-mail: ayele_taye@yahoo.com
}

Received: June 25, 2016

Accepted: August 8, 2016

Online Published: August 16, 2016

doi:10.5430/ijhe.v5n3p217

URL: http://dx.doi.org/10.5430/ijhe.v5n3p217

\begin{abstract}
This paper describes the experiences gained from the established statistical collaboration canter at Hawassa University in May 2015 as part of LISA 2020 network. The center has got similar setup as LISA of Virginia Tech. Statisticians are trained on how to become more effective scientific collaborators with researchers. The service has been delivered from May 2015 to June 2016. The University has a well established and strong academic graduate programs of statistics. The master programs are: Applied Statistics, and Mathematical and Statistical Modelling launched in 2008 and 2010, respectively. They are research based studies. The programs have produced about one hundred ninety graduates to-date, with current enrollment of over fifty students. The doctoral program started in 2013 with enrollment of ten students. The graduate students are the main role players as statistical collaborators at the center. The collaborators and clients have revealed positive feedback about the services. It is observed that the collaboration scheme seem works well and to have an impact on research quality of the non-statistician researchers. The role of statisticians is found to be important in the scientific researches of the University so as to meet the societal needs. The collaboration practice has a potential to enhance the statistics education and research at the department itself. The center needs to be strengthened and expanded for greater services and sharing experiences with other similar higher institutions.
\end{abstract}

Keywords: Collaboration, Graduate studies, Statistics education

\section{Introduction}

There are thirty three public universities in Ethiopia with given missions of teaching, research and community services. Each university is involved in community based researches so as to improve the livelihood of the people. They are expected to conduct quality researches and effective management of extension works to solve the societal problems. Collaboration among scientific community with specially the role of statisticians seems crucial.

Hawassa University $(\mathrm{HwU})$ is one of the biggest higher education institutions. It is located in the Hawassa city which is about $270 \mathrm{~km}$ or 168 miles north of the capital city Addis Ababa. The university consists of over 40 graduate and 60 undergraduate programs in diversified fields of studies in science, technology, engineering, and mathematics, with over 30000 students.

Several faculty researchers and graduate students have been conducting researches. The University focuses on technology villages in the rural and urban areas in which the researches are expected to make impacts on the livelihood of the residents.

The country's demand for statistics usage is much more than ever before. It is believed that statisticians can play great roles in different sectors of the county's economy. Statistics education is keeping growing, where almost all universities get undergraduate programs. Only few have graduate programs in statistics. There are 40 statistics programs in the country among which are $\mathrm{BS} 65.0 \%$, MS $27.5 \%$ and $\mathrm{PhD} 7.5 \%$.

Statistics department at HwU has a vision to be the centre of excellence in statistics, and a mission of teaching, research and community service. The community service includes consultancy and collaboration services. LISA like program is newly introduced at the department in order to provide statistical collaboration services and enhance the statistics graduate programs. The purpose of this study is to report the experience gained and the importance of statistical collaborations. 


\section{LISA 2020 Program}

The Laboratory for Interdisciplinary Statistical Analysis (LISA 2020) is a special program established at the Department of Statistics, Virginia Tech. It aims to train statisticians from developing countries to become effective collaborators who could help enable and accelerate research to solve real-world problems (www.lisa.stat.vt.edu/ LISA2020). LISA 2020 strives to unlock the collaborative potential of technically trained statisticians, who in turn will unlock the research potential of their collaborators and teach the next generation of statisticians to do the same. These collaborations, now with the power of statistical thinking open to them, will be key to improving human welfare.

See www.lisa.stat.vt.edu/LISA2020/sites/default/files/The-LISA2020-Program-to-Build-Statistics-Capacity-and-Researc h-Infrastructure-in-Developing-Countries.pdf.

LISA 2020 is building statistics capacity and research infrastructure in developing countries, and contributing towards building capacity and infrastructure for global science. So far it has assisted establishment of five statistical collaboration laboratories: two in Nigeria, one in Tanzania, one in Ethiopia, and one in Brazil. The program works towards having a network of at least twenty such laboratories by the year 2020 across the developing countries.

According to Vance (2015), statistical consultation helps a client answer a statistical question, while statistical collaboration helps answer a research or business question. The labs should focus on statistical collaboration than statistical consultation. Collaborators would follow specific processes while communication with the nonstatistician researchers. The author also reported that LISA 2020 program helps the newly trained collaborative statisticians create statistical collaboration laboratories of their own in their home universities or institutions. Each of these laboratories will foster education in collaborative statistics and will promote the proper application of statistics to solve real-world problems. One statistician who is trained to communicate and collaborate with nonstatisticians can enable and accelerate 50 or more research projects per year.

Olawale (2012) states the importance of statistical consulting and the need to improve the practice of statistical consulting among young statisticians in Africa by including it in the curriculum of statistics programs in all African Universities and institutions of higher learning. The author also states the need to establish statistical consulting units in African universities.

In general, LISA experience shows that graduate students of statistics can benefit a lot from the collaboration program in terms of technical, non-technical and job related impacts. This is in addition to the contribution to the quality of researches in other fields.

\section{Statistics Education and Global Initiatives}

Statistics is globally advancing in theory, methods and applications. Today, standard and competent statistics education is available worldwide and is supported by the high computational facilities.

Statistics has a role to play in everyday life and in making decisions. From simple data analysis to complex statistical modelling, it affects human thinking, behavior and language. The more improvement in statistical usage, the better informed decision to make.

Lindsay et al (2004) report that statistics is getting attention and many opportunities. The London Workshop for Statistical Science in 2013 report also indicate that statistics has a good future as quoted here below:

"The view of statistics that emerged from the London workshop was one of a field that, after three centuries, is as healthy as it ever has been, with robust growth in student enrollment, abundant new sources of data, and challenging problems to solve over the next century."

Global initiatives of Statistics have greatly promoted its usage. To mention some are: The World of Statistics, Statistics Without Borders and LISA 2020. The World of Statistics promotes statistics and its applications globally (www.worldofstatistics.org). Statistics Without Borders promotes statisticians to work with researchers in health area for global benefits in health (http://community.amstat.org/statisticswithoutborders). LISA 2020 is an innovative program building international network of statistical infrastructure of statistics laboratories. It promotes the use of Statistics in researches in developing countries through local collaborations.

Data size and complexity is growing, and so is the demand for statistics and statisticians. Statisticians are expected to work in collaboration with scientists locally and globally in searching for the 'right' solutions. 


\section{Statistics Education at $\mathrm{HwU}$}

HwU has a well established and strong academic programs of statistics. The statistics department's thematic research areas include statistical inference, probability, statistical modelling, stochastic processes, Bayesian methods, MCMC techniques, spatial data analysis and econometrics. Application areas include health, agriculture, biological process, education, social, business, economics, environment, transportation and communication.

The academic programs are research based studies. Students learn and practice on how to conduct researches and make standard presentations.

Bachelor program: is of three years duration offering BSc degree in Statistics. It was launched in 1995. So far about 850 graduated and 250 has enrolled.

Master program: is of two years duration. There are two master programs teaching statistics: MSc Applied Statistics launched in 2008 and MSc Mathematical and Statistical Modelling launched in 2010. The later is the joint program of Statistics and Mathematics Departments. The maser programs are both research based studies.

The MSc Applied Statistics program provide students with basic and modern statistical theory and methods. Students explore statistical computations and applications. The MSc Mathematical and Statistical Modelling program provides students with a broad and thorough background in mathematical disciplines: mathematical modelling, numerical analysis, probability and statistics. Students explore modern computational methods and various applications of statistics and mathematics.

These master programs have produced about one hundred ninety graduates to-date, and has current enrollment of fifty students.

Doctoral program: is of three-four years duration offering $\mathrm{PhD}$ degree in Statistics. It is launched in 2013. It currently has enrollment of ten students. Supervisions and course teaching are being carried out in teams involving collaborations of local and international Professors.

The graduate students get trainings to be able to conduct researches, make standard presentations, and get computational skills in software such as R, Stata, Minitab, SPSS, SAS and Octave. Report writing is using mainly MS Word and Latex and presentations using Powerpoint and Beamer. Our experience shows that students are motivated to conduct researches that can address real societal problems.

In the country context, sectors' demand for statistics usage is also growing. Students' interest to statistics education is considerably increasing. This implies the need to nurture the collaboration between statisticians and scientists.

\section{Established Statistical Collaboration Center at HwU}

Having strong graduate programs and coming to know about global initiatives like LISA 2020, there came a demand to establish LISA-like statistical laboratory at HwU. A statistical collaboration center was established at the University in May 2015, as part of the LISA 2020 networks. The center can be described as follows.

Rationale: Scientists and graduate students at the University have growing demands for Statistical supports at various levels. There has been a gap between the demands of the researchers and availability of services from the statisticians except few efforts. Statistics Department has developed a staff capacity with training by LISA2020 to deliver the statistical supports to researchers. The establishment of the Statistical Collaboration Center at international standard similar to LISA of Virginia Tech enables us to promote and enhance quality of researches at the university.

Vision: Best quality research for solving societal problems and improving livelihood of the people.

Mission: The statistical collaboration center delivers statistical supports so as to enhance research quality through consultancy and follow-up collaborations scheme with the researchers at the university.

Services: The center delivers statistical services at various stages of research: problem formulation, design of experiment and survey, data collection, data coding and entering, choosing models and data analysis, model selection and diagnosis, interpretation of results, and paper write-up. Modality of the service has three forms:

- Statistical walk-in consultancy service - shorter time visits

- Statistical collaboration service - longer time collaboration and follow-up

- Statistical training service - training on selected topics and software

Beneficiaries: Researchers (clients) improve their research quality and outputs. Faculty and graduate students of Statistics (statistician collaborators) gain motivation for applied researches, comprehend their statistical knowledge 
and computational skills to enhance their statistical thinking and reasoning. They can also develop communication skills and critics on research. Ultimate beneficiaries are the communities at large as users of research outputs and outcomes.

Human Resource: The center has a coordinator and an assistant coordinator. It expected to have an administrator. Statistician collaborators are volunteer faculty members, $\mathrm{PhD}$ and MSc students of statistics at the department.

The center is located at the main campus of the University. It has got facilities required including an office. The center is functioning well with some flow of client researchers.

\section{Results and Lessons Learned}

The center has been functioning well with some flow of researcher clients during May 2015 to June 2016. Most of the clients are graduate students working on their master thesis researches. The statisticians, who are faculty members and graduate students of statistics, have shown high interest to work as collaborative statisticians at the center. They are trained on how to be an effective collaborator with a non-statistician researcher. They are delivering the statistical services for the faculty and graduate student researchers at the university. The faculty researchers and graduate students had comfortably received the collaboration service at the center.

The service delivered by the center can be summarized as follows: service frequency was 46 sessions of collaborations for 36 researchers from various fields. The researchers were from Natural Science and Mathematics (6), Social Science (15), Sport Science (4), Agriculture (8), Health (1) and Engineering (2). Total service time was estimated to be over 210 hours. Almost all services were the statistical walk-in consultancy services. Five PhD students and three faculty members worked as statistical collaborators.

Two of cases are presented here as examples:

Client 1: Faculty member conducting a funded research.

Problem: improve student's reading and communicative skills in English language.

Question: determine statistical model to analyze the data.

Statistician collaborator: suggested appropriate statistical methods to be linear regression and correlation analyses with variable selection among predictors.

Client 2: PhD student of education.

Problem: improve educational curricula that can produce qualified graduates at higher institutions.

Question: Determine statistical methods to analysis data on various indicators of curriculum quality. Help analysis.

Statistician collaborator: suggested method was multivariate analysis. Data on MS Excel imported to SPSS. Analysis and interpretations of results were made.

The establishment of the statistical collaboration center has created a conducive professional environment at the department. These are opportunity to work with each others, sharing knowledge and skills, learning more about other fields and respective problems, enhancing teaching-research of statistics, increasing competency of graduate students and faculty members. It has also helped to minimize the statistician's inconveniences that would have been caused due to the informal consultancy service, by making it formal and with more efficiency of professional service delivery. The program is hoped to eventually play the important role in enabling and accelerating researches at the university to solve real-world problems towards improvement of livelihood of the people.

\section{Challenges and Plans to Overcome Them}

The challenges recognized so far with suggested solutions are summarized as follows:

The service delivery has started with volunteer collaborators and center administrators. As the service consumes time and energy, there is a tendency among the statisticians to look for incentives. One approach employed is certification of service as an incentive. Another is to convert time of service delivered to staff load that the university can recognize. The third option would be to finance the center with annual budget that includes some payments.

There is unstable internet connection that may affect the service delivery. Stand-alone PC, laptops and printed books are to be used when connection is down. There is certain level of lack of experience among collaborators to work as effective collaborative statisticians. Follow-up trainings and updates need to be implemented. 
The department wishes to strengthen the center and expand its services, increase flow of researchers by promoting the available service, and extend the service to handle researchers outside university. It also would like to share experiences with other universities in the country and with other labs under LISA 2020 networks.

\section{Concluding Remarks}

The statistical collaboration center is well functioning filling the gap of lack of statistical supports for researchers at the University. The collaboration enabled the statisticians to work with the professionals from variety of fields for better quality researches. Working as collaborative statistician is enjoyable and is an opportunity to develop statistical skills and knowledge.

It was observed that the collaboration scheme seem to have an impact on the research quality at the University to serve the societal needs. It has a potential to enhance the statistics education and research and hence strengthening the graduate programs. The department has a plan to strengthen the center and its services through follow-up trainings of the statistician collaborators and expand the service delivery to other campuses of the University.

Recommendation: We would increase flow of client researchers by promoting the available collaboration services, extend the service to meet demands of researchers outside the University, share experiences with other labs under the LISA 2020 network, and share our experience with other universities in the country. Any university having graduate programs of statistics would adopt the LISA 2020 model.

\section{Acknowledgements}

The author would like to express gratitude to Prof Eric Vance, Department of Statistics, Virginia Tech, for his advises and encouragement while writing this paper.

\section{References}

LIAS. (2020). www.lisa.stat.vt.edu/LISA2020 (accessed in December 2015).

Lindsay, Bruce G., Jon Kettenring, \& David O. Siegmund. (2004). A Report on the Future of Statistics. Statistical Science, 19(3), 387 - 407. http://dx.doi.org/10.1214/088342304000000404

London Workshop Report. (2013). A Report of the London Workshop on the Future of the Statistical Science,

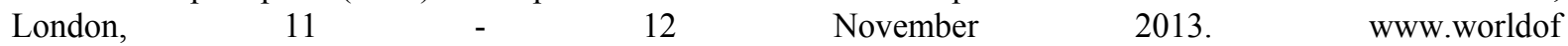
statistics.org/wos/pdfs/Statistics\&Science-TheLondonWorkshopReport.pdf (accessed in January 2015)

Olawale, AO. (2012). Fostering the Practice and Teaching of Statistical Consulting among Young Statisticians in Africa. Journal of Education and Practice, 3(3).

Vance, E. (2015). A Presentation: The LISA2020 Program to Build Statistics Capacity and Research Infrastructure in Developing Countries. www.lisa.stat.vt.edu/ LISA2020/sites (accessed in December 2015).

Vance, EA. (2015). Recent Developments and Their Implications for the Future of Academic Statistical Consulting Centers. The American Statistician, 69(2), 127-137. http://dx.doi.org/10.1080/00031305.2015.1033990

wiki.math.ntnu.no/mastmo (accessed in December 2015).

www.community.amstat.org/statisticswithoutborders (accessed in January 2015).

www.worldofstatistics.org (accessed in January 2015). 